\title{
OFF-élia: Performatividade drag no contexto de Hamlet
}

\author{
LARA BARBOSA COUTO \& MARTHINS MACHADO
}

The present article intends to expose the results of the procedures of creation from the inversion of genres in the construction of the performance Vértices. The study is based on the investigation of devices related to the Drag Queen culture in conjunction with Contemporary Theater, in order to assist in the construction of poetic paths for the soloist. In order to conceive the interweaving between Drag and artistic construction for theater, with academic reflection on the history of gender inversion throughout theater history, the boundaries between expression of gender identity and artistic performance and its results in the scenic construction of the theatrical performance Vértices.

THEATRE / DRAG QUEEN PERFORMANCE / SCENIC CONSTRUCTION / QUEER THEORY

Por reunir elementos de diversas áreas artísticas, a atividade drag configura uma performatividade de difícil delineamento. Tradicionalmente compreendida como uma performance transformista, o desempenho de um artista drag pode articular características oriundas das funções de ator, dançarino, cantor, maquiador, figurinista, diretor, dentre outros. ${ }^{1}$ Entendendo a multiplicidade que atravessa a atividade drag, uma pesquisa realizada dentro do curso de Artes Cênicas da Universidade Vila Velha (UVV-ES) levantou questionamentos acerca de recorrências que caracterizam a atividade $d r a g$, questionando aspectos que diferem um artista Drag Queen de outras atividades transformistas. O espaço de experimentação de tais questões se deu dentro do processo criativo do espetáculo Vértices, sobre Hamlet. A peça é uma adaptação do texto Hamlet, de William Shakespeare. A obra tem direção de Lara Couto e é representada pelos atores Marthins Machado (no papel de Ofélia) e Amanda Amorim (no papel

1 O termo transformismo é usado para se referir a uma pessoa que veste roupas usualmente próprias do sexo oposto com intuito essencialmente artístico (drag queen e drag king) sem que tal atitude interfira em sua orientação sexual ou identidade de gênero e que se diferem dos crossdressers, ou travestis, que se vestem como pertencentes ao sexo oposto para prazer pessoal, sexual, erótico ou emocional. 
de Hamlet). Enquanto aliava pesquisa acadêmica e criação teatral, a rotina de investigação procurou desenvolver o espetáculo a partir do tensionamento de recursos do teatro contemporâneo e a performance drag, explorando possibilidades de aproximação e distanciamento entre o que seria a interpretação de um ator transformista e a performatividade de um artista drag.

O ponto de partida no processo de criação cênica e adaptação do texto dramatúrgico Hamlet se deu através da transferência de uma maior autonomia para os atores/performers na escolha dos fragmentos textuais a serem levados para a sala de ensaio, que poderiam pertencer ao texto de referência, a outras fontes dramatúrgicas ${ }^{2}$ ou ainda articular escritas pessoais. Esta maior responsabilidade autoral é, por exemplo, um aspecto que pode ser identificado dentro da performatividade drag, na qual o artista muitas vezes idealiza e constrói seus produtos sozinho: personagem, texto, figurino, maquiagem, dentre outros.

Outra tendência na atividade $d r a g$ é a reincidência de uma mesma personagem em diversos números, de forma que não é incomum que a construção drag de uma artista se assemelhe a uma espécie de alter ego de si próprio, uma criação elaborada a partir de traços, características e gostos pessoais. $\mathrm{O}$ ator Marthins Machado, que já trabalhava anteriormente com performances $d r a g$, elabora a maior parte de seus números com a personagem Lara Lestrange, figura que desenvolve especialmente apresentações de dança e dublagem e se inspira em ícones negros da cultura pop, como Rihanna e Beyoncé. Dentre as referências usadas para as experimentações em torno de Ofélia, a própria Lara serviu de inspiração, cedendo não apenas figurinos, perucas e adereços, como elementos de sua gestualidade e o interesse pela representatividade das mulheres negras.

Trata-se de um processo de criação que ultrapassa as fronteiras da realidade ficcional proposta pelo texto de referência, que serve de pilar inicial para a sobreposição de diversos outros modelos, a começar pelo próprio ator e trabalhos por ele realizados anteriormente. Marthins trouxe a demanda de experimentação das possibilidades drag dentro do contexto teatral e a provocação de usar a personagem Ofélia como um caminho para discussão de questões relacionadas à temática queer e a questões de gênero.

A discussão de gênero já é um assunto de grande relevância dentro da linguagem drag, razão pela qual esse tipo de atividade costuma tecer interessantes diálogos com a comunidade LGBTT e a teoria queer.

2 A peça usou ainda fragmentos do texto Hamlet-Máquina, de Heiner Müller. 
Guarcira Lopes Louro (2012) apresenta o queer como uma teoria de caráter esdrúxulo e pouco normativo, manifestações excêntricas que não têm pretensões de integração e que assumem o desconforto da ambiguidade. «Queer é um corpo estranho, que incomoda, perturba, provoca e fascina» (Louro, 2012: 8). Em outras palavras, a comunidade queer pretende atuar na contramão de regras socialmente aceitas, com ênfase na negação de uma heteronormatividade homofóbica e interesse por maneiras pouco convencionais de expressão de gênero e das relações interpessoais. O queer tende a denunciar a delimitação de características específicas que referenciam cada gênero, atitude que se repercute em estruturas hierarquizadas e coercivas no entendimento das funções atribuídas ao feminino e ao masculino.

O discurso queer assume o lugar da subversão, lugar esse que por vezes entra em atrito com as reivindicações da comunidade LGBTT. Isso porque o movimento gay propõe uma visão que compreende a homossexualidade como algo normal, assim como a heterossexualidade. Já a política queer, conforme Joshua Gamson (2002), assume a etiqueta da perversidade para destacar a norma por trás daquilo que é considerado normal, seja a respeito da heterossexualidade ou da homossexualidade. Queer não seria se rebelar contra a condição marginal, mas desfrutá-la. Gamson aponta que ser queer é romper com a relação de paralelismo com a heteronormatividade, evitando a repetição de estruturas coercivas. Em virtude disso, a discussão queer abrange uma diversidade de sujeitos que atuam no intuito de provocar estranhamento na forma de pensar as construções de identidade.

É nesse sentido que a atividade drag se desenvolve. Seja na representação de figuras mais sutis ou caricaturadas, a atividade explora, debocha e denuncia procedimentos de construção do feminino e masculino. Nesse jogo de subversão, a orientação sexual do artista drag ou sua identidade de gênero constituem um fator irrelevante. Fazendo uso da proposição de Ana Paula Vencato (2002) é possível entender que as Drag Queens são atores quase sempre transformistas, mas que não fazem uso da indumentária do gênero feminino em seu cotidiano, o que os difere das travestis e das Crossdressers. A esse respeito, define Jaqueline de Jesus (2012: 10):

Travestis: Entende-se, nesta perspectiva, que são travestis as pessoas que vivenciam papéis de gênero feminino, mas não se reconhecem como homens ou como mulheres, mas como membros de um terceiro gênero ou de um não-gênero. 
Crossdresser: Pessoa que frequentemente se veste, usa acessórios e/ou se maquia diferentemente do que é socialmente estabelecido para o seu gênero, sem se identificar como travesti ou transexual. Geralmente são homens heterossexuais, casados, que podem ou não ter o apoio de suas companheiras.

Transformista ou Drag Queen/Drag King: Artista que se veste, de maneira estereotipada, conforme o gênero masculino ou feminino, para fins artísticos ou de entretenimento. A sua personagem não tem relação com sua identidade de gênero ou orientação sexual.

São diversas as formas de vivência transgênero. Há a expressão de vivência de identidade (o que é exemplificado por transexuais), onde o indivíduo vive e se identifica com essa subversão de sua identidade cisgênero para transgêneros ou de não gênero (travestis). ${ }^{3}$ Ocorre também a vivência de funcionalidade (representado por Crossdressers, Drag Queens e Drag Kings) que usam da indumentária do gênero oposto temporariamente. $\mathrm{O}$ sujeito que se coloca em estado de transexualidade funcional não sente necessariamente a necessidade de mudar seu gênero binário. Um ponto a ser destacado é o cunho contracultural da vivência funcional das drags, que se utilizam de normas padronizadas do gênero para anarquizar. ${ }^{4} \mathrm{~A}$ exacerbação dos códigos (masculinos e femininos) agride, perturba e abre questões:

\begin{abstract}
A performance Drag brinca com a distinção entre a anatomia do performista e o gênero que está sendo performado. Mas estamos, na verdade, na presença de três dimensões contingentes da corporeidade significante: sexo anatômico, identidade de gênero e performance de gênero. Se a anatomia do performista já é distinta de seu gênero, e se os dois se distinguem do gênero pela performance, então a performance sugere uma dissonância não só entre sexo e performance, mas entre sexo e gênero, e entre gênero e performance. (Butler, 2003: 196)
\end{abstract}

Compreendendo que o drag não pode ser considerado parâmetro para identificação de gênero ou sexualidade, destaca-se o caráter artístico que

3 De acordo com Jesus (2012), cisgênero é «um conceito que abarca as pessoas que se identificam com o gênero que lhes foi determinado no momento de seu nascimento, ou seja, as pessoas não-transgênero».

4 Surgida nos Estados Unidos na década de 1960, a contracultura pode ser entendida como um movimento de contestação de caráter social e cultural. Nasceu e ganhou força, principalmente entre os jovens desta década, seguindo pelas décadas posteriores até os dias atuais. 
este sujeito desempenha durante suas aparições. Victor Turner (1987) aponta que a ação performática é uma forma dos seres humanos se comportarem. A performance é lúdica e tem potencial persuasivo. Os atores performáticos, através deles mesmos, têm um potente gerador de poder subvertente e transformador do statu quo social, o que situa o drag neste lugar de arte que inquieta e inflama discussões a sua volta. Ao exagerar os códigos, o drag ajuda a lembrar que o corpo social de cada gênero é uma construção inventada e culturalmente ratificada em sociedade. As Drags se posicionam entre os limiares do gênero a fim de subverter padrões estabelecidos pela cultura. Esses conceitos apresentados, tanto na ótica de Butler como em Louro, refletem a contestação de lógicas e normas sociais hierarquizadas.

\begin{abstract}
A Performance enquanto linguagem artística mostra-se como uma possibilidade para o estudo das representações simbólicas a partir dos modos de usar o corpo, ou melhor, como o artista performático se serve do corpo para levantar questionamentos sobre os fenômenos sociais, levando-se em consideração de que cada cultura detém sistemas simbólicos que fomentam os hábitos que são informados por uma tradição Ihe são próprias. (Mauss, 1974 apud Barbosa, 2010: 1199, grifos do autor)
\end{abstract}

Nessa perspectiva, o drag se localiza como linguagem performática que subverte uma lógica social vigente através de uma sátira-denúncia, onde padrões de performatividade do gênero impostos são ironizados, representados ou questionados. Ao mesmo tempo em que abre mão de uma linearidade nas apresentações, aguça outros canais de percepção.

Na década de 1970 eram mais recorrentes apresentações drag calcadas no exagero da figura feminina e na representação de tipos andrógenos. A partir dos anos noventa, no entanto, outros estilos ganharam destaque dentro da cena Drag Queen, que não mais utilizavam o exagero do referencial feminino e se dedicavam à performance de músicas remixadas e danças extravagantes, a exemplificar o bate cabelo. Atualmente a atividade $d r a g$ não performa apenas sobre a separação binária entre gêneros masculinos e femininos, mas apresenta questionamentos sobre a representação de diferentes modelos dentro da sociedade. Alguns gêneros discutem mais fortemente padrões de beleza impostos pela cultura, seja reafirmando esses elementos ou criticando o seu potencial de opressão sobre os corpos. Outras modalidades se ancoram na identidade de gênero como construção, expondo o artifício por trás das caracterizações 
e as possibilidades de transgressão da separação simplista entre gênero masculino e feminino. Outros estilos levam a performance na direção de uma criação extra-humana, adotando novos modelos no planejamento da criação, como animais ou imagens extraterrestres. Por fim, algumas modalidades trabalham a partir de elementos da cultura pop, tomando como inspiração figuras amplamente conhecidas do show business.

Conforme a atividade drag se tornou cada vez mais complexa, novos termos foram adotados para diferenciar a multiplicidade de estilos. O surgimento de novas modalidades contribuiu também para a relativização do conceito de drag. A arte, que tradicionalmente mostrava artistas performando o gênero oposto, se abriu para um leque de possibilidades. Ao longo das investigações, a pesquisa conseguiu elencar doze estilos diferentes de atividade drag. Este delineamento explicitou as possibilidades de recurso que o processo criativo poderia fazer uso. A ideia não era escolher uma única modalidade de drag, mas mesclar variados elementos ao longo do espetáculo. Esta escolha influenciou aspectos fundamentais da representação estética da personagem Ofélia, pois a colocou em movimento, num processo de transição/construção de sua própria identidade ao longo da peça. Em virtude disso, aspectos da caracterização são modificados no decorrer do espetáculo, com a inserção de novos figurinos e acessórios. Essas mudanças na forma de se vestir e agir dialogam com o próprio processo de empoderamento da personagem e valorização da sua própria individualidade além dos padrões de comportamento a ela impostos. Dentre as principais modalidades drags que inspiraram a criação, estão:

$>$ as andrógenas (ou Club Kids) se colocam na fronteira entre o masculino e feminino. Esta modalidade contraria o entendimento comum de que a atividade drag queen se baseia necessariamente na representação da figura feminina. As andrógenas quase sempre se ancoram nas referências punk-rock, futurista e excêntrica para compor suas caracterizações, inserindo peças da indumentária masculina e feminina aos seus figurinos;

$>$ o show stopper é um estilo mais recente de drag, caracterizado por uma menor preocupação com a aparência estética, utilizando um estilo despojado para fazer $d r a g$, sem grandes ornamentações. Além disso, esse estilo de drag se destaca por terem performance de dublagem e dança intensas, onde o foco não é a vestimenta e a maquiagem mas sim o potencial do desempenho (dançando, cantando ou dublando); 
$>$ fish (ou fishy) é uma das modalidades mais femininas de representações drag. No meio drag, agir ou ser fishy é sinônimo de feminilidade extrema. Esse estilo trabalha baseado na representação social da mulher, usam roupas fashion (dentro das tendências mais recentes da moda), e fazem shows performáticos de dança e dublagem, não se limitando apenas à representação da beleza feminina;

$>$ as impersonator (ou covers) são Drag Queens que utilizam do trabalho de cantoras famosas (na maioria da música $p o p$ ) para suas performances. Essas drags se dedicam a fazer de suas apresentações um simulacro, não apenas da aparência, mas do estilo de apresentação das artistas homenageadas.

DA ARTICULAÇÃo DE DIVERSOS ESTILOS DRAG ATÉ A CONSTRUÇÃo DE UMA «OFF-ÉLIA»

Ofélia é uma personagem cujo percurso pode ser entendido como controverso e de muitas significações em aberto. Dentro da abordagem dada pelo ator Marthins Machado em diálogo com a equipe, a representação de Ofélia se centrou principalmente em dois aspectos da trajetória da personagem. No primeiro, a personagem simbolizou o processo de domesticação do comportamento feminino, a necessidade de obedecer, de casar virgem, ser bem-educada, de resistir às investidas masculinas, usar roupas modestas, controlar a própria lascívia e servir aos homens à sua volta: ao pai, ao irmão, ao marido. Num segundo, sua loucura foi compreendida como sua própria possibilidade de libertação dos padrões impostos. O delírio abre margem para a manifestação de suas necessidades mais reprimidas, para a sua espontaneidade calada, até o ápice do gesto extremo e o encontro fatal com o rio.

A respeito da morte da personagem, a equipe de criação do espetáculo preferiu considerar a hipótese do suicídio, apresentando a morte como uma escolha. Esta opção conferiu maior poder de decisão à personagem em seus momentos finais, considerando especialmente suas poucas oportunidades de fazer escolhas a respeito do direcionamento da própria vida. Ao cair no rio, Ofélia conseguiria, enfim, selar o próprio destino, rompendo os laços que a prendiam ao Hamlet, à memória do pai e aos papéis que socialmente lhe eram impostos.

Ofélia abriu campo para a criação de OFF-élia, antimodelo elaborado pelo ator Marthins Machado e personagem levada à cena em Vértices, sobre Hamlet. Através de OFF-élia, Marthins procurou dizer o que Ofélia 
não diz justamente por estar inserida num contexto social no qual não pode ter voz ativa. Diante do relacionamento da personagem com Hamlet, Polônio e Laertes, o ator prefere uma Ofélia que vai à luta e fala o que não poderia ser dito na versão original, pensamentos e opiniões que são levados com ela quando se afoga no rio.

Baseado nas considerações do ator e seu desejo por dar maior protagonismo e voz à personagem, a construção de $O F F$-élia se estabeleceu através da criação de uma série de solos que poderiam ou não se basear na dramaturgia de Shakespeare. Ao longo dos ensaios se agudizou a tendência demonstrada por Marthins de se afastar das cenas em que Ofélia aparecia na dramaturgia original para chamar a atenção para tudo o que ela poderia ter sido. Por esse motivo, a narrativa do espetáculo fez a licença poética de subverter a trajetória descrita na peça de Shakespeare para apresentar a personagem desde o começo como morta. OFF-élia aparece, assim, como um espectro que se coloca em relação com Hamlet. Ela revê passagens de sua vida após ter transgredido, chamando a atenção para as diferentes forças coercivas com as quais teve contato em vida.

Até o momento já foram apresentados três referenciais que contribuíram para a elaboração de $O F F$-élia: a personagem Ofélia (antimodelo), Lara Lestrenge e o próprio ator, Marthins Machado. O quarto referencial a se sobrepor surgiu como outra inquietação do ator, que expressou o desejo de usar mais uma referência, dessa vez uma figura pública que para ele trazia calor, força e indignação à composição: a pintora mexicana Frida Kahlo.

Frida Kahlo é considerada um ícone do feminismo no mundo inteiro. Não apenas a sua produção artística, mas sua biografia e personalidade inspiram diversos debates sobre comportamento e representação da mulher. Tendo como principal tema de suas obras o autorretrato, é possível acompanhar através de suas pinturas, sua inquietação perante o confronto consigo mesma em diferentes situações. Nas telas, Frida recorrentemente aparece em situações dolorosas. Em diferentes quadros a artista está chorando, sangrando, prostrada numa cama, pensando na morte. Em outras, é possível ver aspectos do seu relacionamento com o próprio corpo, violentamente atingido por uma barra de ferro durante um acidente de ônibus, aos dezessete anos. Por conta do acidente, Frida se submeteu a diversas cirurgias ao longo da vida e se viu impossibilitada de ter filhos, sofrendo três abortos. Retratou ainda questões referentes à sua sexualidade e seu relacionamento com o também artista Diego Rivera, com quem manteve um casamento conturbado por mais de vinte anos. 
Apesar de não haver registros de seu engajamento direto nas causas feministas, Frida transgrediu expectativas de comportamentos esperados de uma mulher de sua classe social e época, questionando padrões estéticos da representação feminina através da maneira incomum com que pintava a si mesma. Frida preferiu ir na contramão da idealização feminina e retratou suas próprias deficiências, seu corpo frágil, e os traumas vividos em decorrência do acidente. Assumiu sua monocelha e os pelos do buço e constantemente aparecia com trajes de tehuana, vestimenta que caracterizava as zapotecas, grupo indígena no qual as mulheres exercem um papel central na realização de diversas funções na comunidade, desde aqueles referentes à vida doméstica como ao trabalho:

O traje que Frida decidiu adotar era o das mulheres do istmo de Tehuantepec, e as lendas em torno delas sem dúvida informaram sua escolha: as mulheres de Tehuantepec são famosas por serem imponentes, sensuais, inteligentes, corajosas e fortes. Segundo o folclore, vivem em uma sociedade matriarcal, em que as mulheres dirigem os mercados, cuidam das questões fiscais e dominam os homens. (Herrera, 2002: 87)

Inspira a construção de $O F F$-élia o percurso desenhado por Frida na exploração de aspectos da sua individualidade. Este movimento envolve aparições em diferentes trajes, desde roupas masculinas a trajes típicos, o que aponta para uma inquietação perante a própria identidade e a maneira como a artista desejava se posicionar no mundo. Sua obra autobiográfica parece seguir o mesmo percurso, evidenciando aquilo que a maioria pretende esconder: suas feridas corporais e emocionais. Em suma, Frida remete ao corajoso confronto consigo mesma, não pela busca de uma essência, mas a partir da experimentação das múltiplas possibilidades do que se pode ser. Em outra instância, a escolha de uma figura de grande popularidade alude ao trabalho das impersonators. No entanto, o desejo de Marthins não era de fazer um cover de Frida Kahlo, mas inserir características observadas na artista à caracterização, além de incorporar elementos de latinidade que deslocassem sua OFF-élia de um contexto europeu e distanciado.

A construção da personagem articulou diferentes estratégias e pontos de referência, fazendo da caracterização um complexo arranjamento de materiais a serem ajustados de acordo com o discurso que se desejava imprimir à obra. Ocorre, dessa maneira, uma aproximação entre os 
procedimentos adotados no processo com a ideia de um ator-compositor defendida por Matteo Bonfitto (1994). Diante das necessidades impostas pelas múltiplas configurações das personagens, Bonfitto defende um ator que coordene diferentes estratégias na construção do desempenho:

\begin{abstract}
[...] independentemente das opções subjetivas presentes em todo processo artístico, os tipos de seres ficcionais aqui examinados abrem a possibilidade de utilização de diferentes elementos, procedimentos e matrizes em seu processo de construção. A utilização de materiais de diferentes naturezas deverá gerar, por sua vez, a necessidade de inserir transcrições entre essas matérias. A busca de sentido de cada material e das possíveis transcrições entre eles envolve, dessa forma, uma competência específica do ator. [...]

Diante da complexidade dos fenômenos teatrais contemporâneos, o ator, a fim de ser criador, precisará saber compor. Mas para poder compor, ele deverá ser capaz de não só de fazer, mas de pensar o fazer. [...] O fazer, com seu sentir e perceber, transforma o pensar. E o pensar, com a força de sua elaboração, transforma o fazer. Assim, o fazer transformando o pensar e o pensar transformando o fazer geram uma espiral incessante. É nessa espiral que se move o ator-compositor. (Bonfitto, 1994: 140-142, grifo do autor)
\end{abstract}

Se colocar diante do processo como um ator-compositor envolve, dentre outras coisas, reforçar a autoria da criação, compreendendo que pode $\mathrm{o}$ ator planejar e gerir os próprios procedimentos de maneira autônoma ou paralela à condução do diretor. No caso de Vértices, a voz da direção privilegiou pôr em cena as visões apresentadas pelos atores Marthins Machado e Amanda Lima, funcionando mais como uma orientação das propostas trazidas por eles para a sala de ensaio.

Uma particularidade fruto desta autonomia foi a escolha determinada por Amanda Lima de não construir o seu Hamlet a partir de elementos da performatividade drag. Havia essa possibilidade, uma vez que existe um estilo que se dedica a ações desta natureza, as chamadas Drag King. São chamadas de Drag King as mulheres que representam o gênero masculino através de números que recorrentemente questionam aspectos do comportamento dito masculino na sociedade, satirizando hábitos e posturas reconhecidos como típicos dos homens. No entanto, a preferência da atriz foi a de se concentrar nas características mais reflexivas da personagem, priorizando a representação de suas angústias interiores e 
questionamentos perante a vida do que questões relativas à representação da sua condição masculina.

Assim como aconteceu com Marthins Machado, o processo de construção de Hamlet se deu através da proposição de variados solos, de modo que a pesquisa não se preocupou inicialmente com a construção de uma coesão entre as propostas. Pelo contrário, pareceu interessante explorar o distanciamento entre figuras que deveriam ser relativamente próximas, mas que na lente do espetáculo parecem habitar mundos completamente diferentes. Por fim, algumas diferenças foram amenizadas quando os solos foram organizados em cenas conjuntas e a rotina dos ensaios possibilitou a contaminação entre as variadas visões. Ainda assim o produto final não perdeu seu caráter fragmentado, a sua desarmonia nos encontros e desencontros de um Hamlet desregulado e uma Ofélia desajustada, figuras que não se confrontam diretamente, mas que se põem frente a frente com suas próprias questões mal resolvidas.

Em outras palavras, é importante evidenciar que não é a mera inversão do gênero que possibilita o cruzamento entre teatro e performatividade drag. Um ator que interpreta uma personagem com o gênero trocado não está enquadrado na linguagem drag se o desempenho não se preocupa em questionar e subverter códigos pré-estabelecidos do que é ser homem ou mulher. Além disso, existem diversas outras ações performativas que caracterizam o repertório de trabalho de uma Drag Queen: canto, dublagem, dança... Alguns desses elementos foram incorporados como cenas do espetáculo, que agregou ainda outros aspectos referentes à identidade visual $\mathrm{drag}$, como maquiagem extravagante, trocas de figurino, perucas exóticas, etc.

Os momentos de dublagem entraram como um ponto de suspensão da narrativa, espaço de transformação da personagem e até mesmo como uma espécie de clímax dentro da encenação. Uma das cenas mais relevantes do espetáculo é a dublagem da canção Mulher do Fim do Mundo:

Na chuva de confetes deixo a minha dor

$\mathrm{Na}$ avenida, deixei lá

A pele preta e a minha voz

Na avenida, deixei lá

A minha fala, minha opinião

A minha casa, minha solidão

Joguei do alto do terceiro andar

Quebrei a cara e me livrei do resto dessa vida 
$\mathrm{Na}$ avenida, dura até o fim

Mulher do fim do mundo

Eu sou e vou até o fim cantar

(Coutinho/Fróes, 2015)

A Mulher do fim do mundo é uma canção interpretada pela cantora Elza Soares, uma das mais importantes artistas negras da Música Popular Brasileira. A música compõe o álbum A Mulher do fim do mundo e retrata a narrativa de uma mulher que testemunha o apocalipse, contexto que se mistura com o próprio carnaval. Diante do trágico desfecho, a mulher do fim do mundo deixa na avenida não só suas lembranças, mas toda a sua visceralidade. A canção termina com seus brados de resistência, nos quais afirma que irá cantar até o fim. É uma música especialmente comovente considerando a frágil saúde da cantora, que nos seus oitenta anos ainda realiza shows pelo país e pelo mundo, embora sobre uma cadeira de rodas.

A música aparece no segundo momento de dublagem do espetáculo, no qual a atitude drag ganha novas proporções, com movimentos ainda mais dilatados. Conforme dubla, a personagem desconstrói sua própria caracterização, desfazendo de seus sapatos, seu figurino e até mesmo da sua peruca. É o desnudamento da conduta social normatizada, a retirada das máscaras, atitude que revela até mesmo a presença do ator/performer Marthins Machado por trás da composição: sai a peruca lisa e mostra-se o cabelo crespo.

A peça até então já havia tecido diálogos com o estilo impersonator, a citar o desempenho sobre a música Love On The Brain, livremente inspirado na cantora Rihanna (intérprete da música). Já a cena de $A$ Mulher do fim do mundo presta homenagem às drags andrógenas, pois estabelecem uma atitude performativa de fronteira entre feminino e masculino conforme apresenta Marthins em cena. Após a dublagem e troca de figurino, OFF-élia passa a usar uma saia de penas que remete ao tipo de caracterização das Fish Queens, onde a saia e corsets fazem menção às roupas usadas pelas mulheres do teatro de revista, ou até mesmo o burlesco. 5 É quando a personagem abraça o seu lado marginal. Para reforçar essa

5 A arte burlesca se refere a um tipo de apresentação teatral que consiste em uma paródia ou sátira. Alguns autores definem o teatro burlesco como descendente direto da commedia dell'arte, «farsa» ou «burla» para uma paródia ou comédia de costumes aparece aproximadamente ao mesmo tempo em que surge a primeira aparição da commedia dell'arte. Burlesco faz parte da categoria estética grotesca, sendo uma representação teatral ou dança. Representação de caráter exagerado, parodiando temas dramáticos com alto teor farsesco, esta forma cômica trata de personagens extravagantes e bufonas. Autores que discorrem sobre o grotesco, citam o burlesco como variante ligada à encenação. 
nova atitude, o espetáculo incorporou um trecho de Hamlet-Máquina, de Heiner Müller:

Eu sou Ofélia. Aquela que o rio não conservou. A mulher com as veias cortadas. Ontem deixei de me matar. Estou só com meus seios, minhas coxas, meu ventre. Rebento os instrumentos do meu cativeiro. Destruo o campo de batalha. Com as mãos sangrando rasgo as fotografias do homem que amei e que se serviu de mim na cama, na mesa, na cadeira, no chão. Toco fogo na minha prisão. Atiro minhas roupas no fogo. Vou para a rua, vestida em meu sangue. (Müller, 1987: 27)

OFF-élia resulta de uma conjunção complexa de referências sobrepostas a elementos do Drag Queen e ao contexto ficcional inspirado por Hamlet. O processo se desenvolveu a partir do entendimento de que o drag não exerce apenas um papel de entretenimento, mas também de militância política acerca de questões de gênero e de sexualidade. Conforme corrompe sua imagem de referência, o ato performativo expõe novas possibilidades de entendimento e expressão da figura. OFF-élia segue tal princípio e se mostra como uma distorção que transgride a dramaturgia original, confrontando-a com o desejo discursivo do ator Marthins Machado.

\section{REFERÊNCIAS BIBLIOGRÁFICAS}

Af F ONso, Frederico Pires (2012), Transgeneridade na Moda: O Vestir em João Nery e Laerte Coutinho, monografia, curso de especialização em Moda, Cultura de Moda e Arte, Instituto de Arte e Design, Universidade Federal de Juiz de Fora, http://www.uff.br/posmoda/files/2013/o5/Transgeneridade-na-moda.pdf.

BAKER, Roger (1994), Drag: A History of Female Impersonation in the Performing Arts, Nova Iorque, New York University Press.

BARB OSA, Eduardo Romero (2010), «O corpo representado na arte contemporânea-O simbolismo do corpo como meio de expressão artística», apresentado no ANPAP - Encontro da Associação Nacional de Pesquisadores em Artes Plásticas «Entre Territórios», Cachoeira, http://www.anpap.org.br/anais/2010/pdf/cpa/ eduardo_romero_lopes_barbosa.pdf.

Berthold, Margot (2005), História Mundial do Teatro, 2. a ed., São Paulo, Perspectiva.

Bonfitto, Matteo (2002), O Ator Compositor: As ações físicas como eixo: de Stanislávski a Barba, São Paulo, Perspectiva.

BUtLER, Judith (2001), O Corpo Educado: Corpos que pesam sobre os limites discursivos do sexo, Belo Horizonte, Autêntica Editora.

- (2008), Problemas de Gênero: Feminismo e subversão da identidade, Rio de Janeiro, Civilização Brasileira. (ed. port. Problemas de Género: Feminismo e subversão da identidade, Orfeu Negro, 2017).

coutinho, A. / Fróes, C. (2015), Mulher do fim do mundo. A Mulher do fim do mundo, Circus/Natura Musical, [CD]. 
GAMSON, Joshua (2002), «Deben autodestruirse los movimientos identitarios? Un extraño dilema», in Rafael M. Mérida Jiménez, Sexualidades transgresoras: Una antología de estudios queer, Barcelona, Icária editorial, pp. 141-72.

GADE LHA, José Juliano Barbosa (2009), Masculinos em Mutação: A Performance Drag em Fortaleza. dissertação de mestrado, mestrado em Sociologia, Universidade Federal do Ceará, Fortaleza, http://www.repositorio. ufc.br/bitstream/riufc/1480/1/2009_Dis_JJBG.pdf.

HER RERA, H. (2015), Frida: a biografia, $4 \cdot^{\mathrm{a}}$ ed., São Paulo, Globo.

JESUs, Jaqueline Gomes de (2012), Orientações sobre identidade de gênero: conceitos e termos, Brasília, s/e, https:// www.sertao.ufg.br/up/16/o/ORIENTA\%C3\%87\%C3\%95ES_POPULA\%C3\%87\%C3\%83O_TRANS. pdf?1334065989.

LOU RO, Guacira Lopes (1997), Gênero, Sexualidade e Educação: Uma perspectiva pós estruturalista, Petrópolis, Vozes.

- (2001), O Corpo Educado: Pedagogias da sexualidade, Belo Horizonte, Autêntica Editora.

- (2004), Um Corpo Estranho: Ensaios sobre a sexualidade e teoria queer, Belo Horizonte, Autêntica.

MÜLLER, Heiner (1987), Quatro textos para teatro: Mauser. Hamlet-Máquina. A missão. O quarteto, trad. Fernando Peixoto/Renato Meastrinel, São Paulo, Hucitec.

PAVIS, Patrice (1999), Dicionário de Teatro, trad. J. Guinsbug/Maria Lúcia Pereira, São Paulo, Perspectiva.

SAN T Os, Joseylson Fagner dos (2010), «Identidades e Performances-Um Olhar Sobre as Drag Queens em Natal», apresentado em XVIII Semana de Humanidades da UFRN, Natal, http://www.cchla.ufrn.br/shXVIII/ artigos/GT2O/JO\%2OFAGNER\%2O-\%20Artigo\%2oSemana\%2Ode\%2oHumanidades.pdf.

- (2010), «Divas, kengas e “dragões”: a (re)construção do corpo entre performances e identidades transformistas em Natal», apresentado na Reunião Brasileira de Antropologia, Belém, https://www.academia.edu/ 2314485/Divas_kengas_e_drag\%C3\%B5es_a_re_constru\%C3\%A7\% C3\%A30_do_corpo_entre_performances_ e_identidades_transformistas_em_Natal_RN_?auto=download.

SHAKESPEARE, William (2001), Hamlet, São Paulo, M. Claret.

StA Is lavsky, Constantin (1976), A Construção da Personagem, Rio de Janeiro, Civilização Brasileira.

VENCATO, Anna Paula (2002), «Fervendo com as drags»: corporalidades e performances de drag queens em territórios gays da Ilha de Santa Catarina, dissertação de mestrado, Departamento de Antropologia Social do Centro de Filosofia e Ciências Humanas, Universidade Federal de Santa Catarina, Ilha de Santa Catarina, https://repositorio.ufsc.br/bitstream/handle/123456789/84381/183795.pdf?sequence=1.

\section{LARA BARBOSA COUTO \& MARTHINS MACHADO}

Lara Barbosa Couto é doutorada em Artes Cénicas pela Universidade Federal da Bahia e professora do curso de Artes Cénicas da Universidade Vila Velha.

Marthins Machado é licenciado em Artes Cénicas pela Universidade de Vila Velha, ator e drag queen (Lara Lestrange). 